\title{
Kinetic model selection and the Hill model in geochemistry
}

\author{
B. D. Turner $\cdot$ B. J. Henley $\cdot$ S. B. Sleap $\cdot$ \\ S. W. Sloan
}

Received: 28 November 2013/Revised: 5 June 2014/Accepted: 11 August 2014/Published online: 23 September 2014

(C) Islamic Azad University (IAU) 2014

\begin{abstract}
This study introduces the Hill model for modelling sorption kinetics and illustrates its efficacy using formal model selection procedures. Although the coefficient of determination $\left(R^{2}\right)$ value can be used to ensure goodness-of-fit of a particular model to a set of data, a measure that incorporates the number of model parameters, such as the Bayesian information criterion, law of iterated logarithm criterion, Akaike information criterion, and the extra sum-of-squares $F$-test is necessary to undertake reliable model selection. This study undertook a formal model selection procedure based on these criteria, in combination with the coefficient of determination, for a range of candidate kinetics sorption models [the pseudo-second order (PSO), the intra-particle diffusion (IPD), Power, Elovich, and the four and five parameter Hill models]. It was found that the model order that statistically best described the data was Hill $5>$ Hill $4>$ pseudo-second order $>$ Elovich $>$ Power $>$ IPD as given by the evidence ratios, information criterion weights and Bayes factors. The extra sum-of-squares $F$-test, only applicable to nested models, confirms the best fit order as Hill $5>$ Hill $4>$ PSO models. Two new parameters ( $T$ and $\left.k_{\text {Hill }}\right)$ have also been defined that give the Hill models a mechanistic meaning directly comparable to the well-defined parameters of the pseudo-second-order model, namely, the pseudo-secondorder rate constant $k_{\mathrm{pso}}$ and the instantaneous sorption coefficient $h_{\mathrm{pso}}$. In the field of geochemistry the use of the four and five parameter Hill models for describing sorption
\end{abstract}

\footnotetext{
B. D. Turner $(\bowtie) \cdot$ B. J. Henley · S. B. Sleap · S. W. Sloan Centre for Geotechnical and Materials Modelling and Australian Research Council Centre of Excellence for Geotechnical Science and Engineering, The University of Newcastle, University Drive, Callaghan, NSW 2308, Australia

e-mail: brett.turner@newcastle.com.au
}

kinetics has been overlooked with many studies favouring the PSO model. It is strongly recommended that the Hill model be considered more widely as a general predictive tool in geochemistry.

Keywords Hill model · Pseudo-second order . Adsorption · Kinetics · Model selection · AIC

\section{Introduction}

The removal of contaminants from aqueous solutions onto solid substrates is an increasingly well utilised remediation method (Robinson et al. 2001). Many studies have investigated modelling sorption system kinetics. For example, Fan et al. (2003) studied the application of pseudo-first order (PFO) and pseudo-second order (PSO) models for fluoride removal by hydroxyapatite, fluorspar, calcite and quartz; Igwe and Abia (2007) investigated the removal of metals using maize cob; Leyva-Ramos et al. (2010) studied fluoride sorption using diffusion and kinetic models; and Dimovic et al. (2011) analysed the removal of $\mathrm{Co}^{2+}$ by bone char using PFO and PSO kinetic models.

A series of studies have also compared linear and nonlinear fitting methodologies for sorption kinetic models, (Ho (2006), Kumar and Sivanesan (2006b), Kumar and Sivanesan (2006a), El-Khaiary et al. (2010) and Chowdhury and Das (2011)). These studies used the coefficient of determination $\left(R^{2}\right)$ to compare between model fits and recommended nonlinear fitting methodologies over linear methods. However, the $R^{2}$ approach does not take into account the number of model parameters and will therefore always favour higher parameter models, and as such, is a poor method for model selection (Johnson and Omland 2004). Methods that account for a model's goodness-of-fit 
$\left(R^{2}\right)$ and its number of parameters are better suited for model selection. Such methods include information criterion (IC) and likelihood ratio tests (LRT).

The most widely used LRT is the statistical F-test which takes into account the number of parameters and data points and compares the fits based on the sum-of-squares. The $F$-test (Eq. 1) does this through statistical hypothesis testing, however, the models must be nested (i.e. the first model is a simplified version of the second).

$F=\frac{\left(\mathrm{RSS}_{1}-\mathrm{RSS}_{2}\right) /\left(d f_{1}-d f_{2}\right)}{\left(\mathrm{RSS}_{2} / d f_{2}\right)}$

where $F$ is the $F$-statistic (ratio), $\mathrm{RSS}_{1}$ and $\mathrm{RSS}_{2}$ are the sum of squared residuals of the less and more complicated models, respectively; $d f_{1}$ and $d f_{2}$ are the respective degrees of freedom [number of data points $(N)$-number of parameters $(p)]$ for the less/more complicated models. Computing the $F$-statistic then allows the $p$ value (probability value) to be found. If the $p$ value is less than a predefined significance level $(\alpha)$, generally $5 \%$, then the simpler model (the null hypothesis) can be rejected. If the $F$-statistic approaches 1 then the simpler model will be the better fitting model and $p>\alpha$.

Model selection based on information criteria has the advantage that it can be used to compare both nested and non-nested models and is simple to interpret. The "best" model is defined as the one with the lowest (most negative) information criterion when comparing models fitted to the same data. Model selection is most commonly carried out using the Akaike Information Criterion (AIC, Eq. 2), after Akaike (1974).

$\mathrm{AIC}=N \cdot \ln \left(\frac{\mathrm{RSS}}{N}\right)+2(p+1)$

where $N$ is the number of data points, RSS is the sum of squared residuals, and $p$ the number of model parameters. The AIC is calculated using the Kullback-Leibler discrepancy (a measure of the distance between the probability density generated by the model and reality (Wagenmakers and Farrell 2004)) and takes into account both a model's goodness-of-fit $R^{2}$ and its number of parameters. However, it has the disadvantage of not being "consistent", meaning it does not guarantee that the probability of selecting the wrong model approaches zero as the number of data points tends to infinity (Foubert et al. 2002; Wagenmakers and Farrell 2004; Stone 2005). Information criterion that are "consistent" include the Schwarz Bayesian information criterion [BIC, Eq. 3, (Schwarz 1978)] and Khinchin's Law of Iterated Logarithm Criterion [LILC, Eq. 4, (Hannan and Quinn 1979; Foubert et al. 2002)].

$\mathrm{BIC}=N \cdot \ln \left(\frac{\mathrm{RSS}}{N}\right)+(p+1) \ln (N)$
$\mathrm{LILC}=N \ln \left(\frac{\mathrm{RSS}}{N}\right)+p \ln (\ln (N))$

where the parameters are as described above.

The BIC is grounded in Bayesian principles and is based on the empirical log-likelihood and does not require the specification of priors. The BIC therefore attempts to identify a posteriori what the most probable model is for a particular data set (Atukeren 2010). The small and large sample properties of the BIC are defined in the literature and document extensive evidence in favour of the BIC over other model selection criteria (Atukeren 2010). The advantages and disadvantages of the AIC and BIC have been discussed elsewhere and for a theoretical discussion the reader is directed to Kass and Raftery (1995), Burnham and Anderson (2002), and Wagenmakers (2007).

The BIC is structurally similar to the AIC but includes an additional penalty for the number of data points and therefore favours simpler models as $N \rightarrow \infty$. Qian and Field (2002) showed that model selection criteria that include a penalty term as an increasing function of the model dimension (i.e. $p$ ) will always select the simpler model, consequently for large data sets the use of BIC and LILC as model selection criterion is preferred. In comparison to the $F$-test, Atukeren (2010) reported that for data with $N>50$ the BIC behaves more conservatively as compared to an $F$-test conducted at the $\alpha=5 \%$ significance level.

It has been normal practice in many fields to accept the "best" model based on the raw AIC, BIC or any information criteria values, with the "best" model having the lowest (most negative) value. This, however, makes it difficult to unambiguously interpret the results (Wagenmakers and Farrell 2004). A better method is to calculate the relative criterion weights for each model with the model having the most statistical confidence being the one with the lowest value (Wagenmakers and Farrell 2004). The information criterion weights, $w_{i}(\mathrm{IC})$, for the $i$ th model, can be found from Eq. 5a, where IC is the respective information criterion (AIC, BIC, etc.).

$w_{i}(\mathrm{IC})=\frac{\exp \left(-0.5 \Delta_{i}(\mathrm{IC})\right)}{\sum_{k=1}^{K} \exp \left(-0.5 \Delta_{k}(\mathrm{IC})\right)}$

$\Delta_{i}$ IC is the difference in information criterion value for the $i$ th model with respect to the information criterion value of the "best" candidate model (i.e. the model having most negative $\mathrm{IC}$ value, $\mathrm{IC}_{\mathrm{min}}$ ) is calculated from:

$\Delta_{i}(\mathrm{IC})=\mathrm{IC}_{i}-\mathrm{IC}_{\min }$

The strength of evidence in favour of one model over another is then obtained by dividing their respective relative weights (further explanation and examples are 
given in Wagenmakers and Farrell (2004)). This is also supported by Motulsky and Christopoulos (2004) who define an evidence ratio (ER):

$\mathrm{ER}=\frac{1}{\mathrm{e}^{-0.5 \Delta \mathrm{IC}}}$

In addition, BIC calculations can also be used to approximate the strength of evidence in favour of one model over another using procedures developed by Jeffreys (1939) as outlined in Kass and Raftery (1995) and Raftery (1995). This involves the calculation of an approximate Bayes factor (BF) without the difficulties of formal Bayesian statistical analysis (i.e. the calculation of a prior). It has been shown (Kass 1993; Kass and Raftery 1995) that the BIC is related to the BF $B$ as shown in Eq. 7.

$2 \ln \left(B_{j k}\right) \approx \mathrm{BIC}_{k}-\mathrm{BIC}_{j}$

where $B_{j k}$ is the BF for of model $j$ versus model $k$, and the BIC values calculated for the models via Eq. 3 . When $1 \leq B_{j k} \leq 3$, there is evidence for model $k$ being preferred but it "is not worth more than a mention", when $3 \leq B_{j k} \leq 20$ the evidence is "positive"; when $20 \leq B_{j k} \leq 150$ the evidence is "strong" and; when $B_{j k} \geq 150$ the evidence is "very strong" (Kass and Raftery 1995). Inspection of Eqs. 5a-7 indicates that the calculation of the $\mathrm{BF}\left(B_{j k}\right)$ is therefore the same as the evidence ratio (Eq. 6) and/or the inverse of the relative weights.

\section{Model background}

Four models commonly used in the geochemical literature include the PSO model, the intra-particle diffusion (IPD), Power, and Elovich models. In addition this study considers two new models based on the Hill model never before used in geochemical modelling.

The PSO model is arguably the most widely used kinetics sorption model and was used in the studies by Blandhard 1984, Ho and McKay (1998b) and Chowdhury and Das (2011). It is often recommended because it considers system heterogeneity (Diaz-Nava et al. 2008). The nonlinear (preferred) form of the PSO equation is:

$q_{t}=\frac{t}{\frac{1}{h}+\frac{t}{q_{\mathrm{e}}}}$

where $q_{t}\left(\mathrm{mg} \mathrm{g}^{-1}\right)$ is the amount of contaminant sorbed at time $t, q_{\mathrm{e}}\left(\mathrm{mg} \mathrm{g}^{-1}\right)$ is the sorption capacity at equilibrium, and the instantaneous sorption coefficient $h=k_{\mathrm{pso}} q_{\mathrm{e}}^{2}(\mathrm{Ho}$ and McKay 1998b), where $k_{\mathrm{pso}}$ is the PSO rate constant $\left(\mathrm{g} \mathrm{mg}^{-1} \mathrm{~min}^{-1}\right)$. The half-life $\left(t_{0.5}\right)$ or time for $50 \%$ maximum removal occurs when $q_{t}=q_{\mathrm{e}} / 2$. Equating this with Eq. 8a it can be shown that

$t_{0.5}=\frac{1}{k_{\mathrm{pso}} q_{\mathrm{e}}}$
The four and five parameter Hill model has been widely used to study sigmoidal dose effect relationships in biochemical, physiological, and pharmacological contexts (Holford and Sheiner 1981; Khinkis et al. 2003). The Hill equation was introduced by Hill (1910) to describe the relationship between oxygen tension and the saturation of haemoglobin (Goutelle et al. 2008) as described by Barcroft and Camis (1909). A variant of the Hill equation has recently been used to describe reaction kinetics in biochemical system (Smadbeck and Kaznessis 2012). However, the Hill model appears to have been overlooked for studying the kinetics of sorption even though there is a strong relationship between the Hill equation (and variations thereof) and the Guldberg and Waage law of mass action (Goutelle et al. 2008) which describes the kinetic aspects of chemical reactions.

The four parameter Hill (Hill 4) model is:

$q_{t}=D+\frac{(A-D)}{1+\left(\frac{t}{k_{\text {Hill }}}\right)^{-n}}$

where $A$ is the maximum (equilibrium) removal capacity $(\mathrm{mg} / \mathrm{g}), D$ is the minimum removal asymptote or the amount of contaminant removed $(\mathrm{mg} / \mathrm{g})$ as $t \rightarrow 0, k_{\mathrm{Hill}}$ (min) is the time when $50 \%$ of the observed removal $((A-D) / 2)$ has occurred (half-life) and $n$ is the Hill parameter (unitless) which reflects the steepness (sigmoidicity) of the curve. $n$ becomes significant in systems where initial inhibition of contaminant removal is observed, for example, where the adsorbate is poisoned (inhibited) or competition for sorption site exists.

The five parameter model (Hill 5) differs from the Hill 4 model in that it allows for asymmetry in the sigmoidal curve by the addition of the asymmetry parameter $E$ (unitless): Varying the parameter $E$ provides significant flexibility in the initial rate and the shape of the curve. Due to the presence of $E$ in Eq. 10a, the half-life time of the reaction can be found from Eq. 10a. By setting $E=1$ (Eqs. 10a and 10b), the Hill 5 equation reduces to the Hill 4 (Eq. 9) and therefore Eq. 10b becomes $t_{0.5}=k_{\mathrm{Hill}}$ indicating that the parameter $k_{\mathrm{Hill}}$ in Eq. 10a is equivalent to the half-life time.

$q_{t}=D+\frac{(A-D)}{\left(1+\left(\frac{t}{k_{\text {Hill }}}\right)^{-n}\right)^{E}}$

$t_{0.5}=k_{\text {Hill }}\left(\left(2^{\left(\frac{1}{E}\right)}-1\right)\right)^{\left(\frac{1}{-n}\right)}$

As the Hill 4 model is a simplified version of the Hill 5 model (e.g. when $E=1$ ), they are considered to be "nested" models (Motulsky and Christopoulos 2004). Similarly it can be shown that the PSO model is a "nested" (simplified) version of the Hill 4 model. Consider the case $n=1, D=0$, and $A=q_{\mathrm{e}}$ (the maximum sorption/removal capacity) the Hill 4 equation, reduces to: 
$q_{t}=\frac{q_{\mathrm{e}} t}{t+k_{\mathrm{Hill}}}$

Re-writing the PSO Eq. 8a becomes:

$q_{t}=\frac{h q_{\mathrm{e}} t}{q_{\mathrm{e}}+h t}$

Equating Eq. 11 with 12 it can be shown that:

$k_{\text {Hill }}=\frac{q_{\mathrm{e}}}{h_{\mathrm{pso}}}$

Therefore, under the given conditions, substituting Eq. 13 into Eq. 11 gives the PSO Eq. (12). Consequently, these models are "nested" indicating that the more complicated Hill models are derived by adding parameters to the more-simple (PSO) model.

The IPD equation has been used to model many systems, (Igwe and Abia 2007; McKay and Poots 1980) and has the form as given by Weber and Morris (1963) in (Ho et al. 2000):

$q_{t}=a t^{0.5}+C$

where $q_{t}\left(\mathrm{mg} \mathrm{g}^{-1}\right), a\left(\mathrm{mg} \mathrm{g}^{-1} \mathrm{~min}^{-1}\right)$ is the IPD rate constant, and $C\left(\mathrm{mg} \mathrm{g}^{-1}\right)$ represents the boundary layer diffusion effects and $t$ is time (min). A good model fit indicates that the rate limiting step of a sorption reaction is likely to be IPD (Weber and Morris (1963) in (Ho et al. 2000)):

The Power model (Eq. 15) is a modified form of the Freundlich equation (Asci et al. 2012) and has been used to describe kinetics in soil systems (Motlagh 2012):

$q_{t}=a t^{b}$

where $q_{t}\left(\mathrm{mg} \mathrm{g}^{-1}\right)$, and $a\left(\mathrm{mg} \mathrm{g} \mathrm{min}^{-1}\right)$ and $b$ (unitless) are rate constants that are calculated from the intercept and slope (respectively) of a linear plot of $\ln (q t)$ versus $\ln (t)$. A good model fit indicates a diffusion-controlled process (Havlin et al. 1985).

The Elovich model, originally proposed by Roginsky and Zeldovich (1943) (McLintock 1967) has been used to describe the sorption kinetics of gases on heterogeneous surfaces (Low 1960) and also to study the heterogeneous sorption kinetics of many types of systems (Chien and Clayton 1980; Ho and McKay 1998a; Igwe and Abia 2007; Pavlatou and Polyzopoulos 1988; Perez-Marin et al. 2007). The traditional linear form of the Elovich model, as given by Perez-Marin et al. (2007) is:

$q_{t}=\frac{1}{\beta \ln (\alpha \beta)}+\frac{1}{\beta \ln (t)}$

where $\alpha$ is the initial sorption rate $\left(\mathrm{mg} \mathrm{g}^{-1} \mathrm{~min}^{-1}\right)$ and $\beta$ is the desorption constant $\left(\mathrm{g} \mathrm{mg}^{-1}\right)$. For the data to be described by the Elovich model, a plot of $q_{t}$ versus $\ln (t)$ should yield a linear fit.
Analysis of model selection methodologies has previously been explored for sorption isotherms (Ho 2004). This study concluded that it is not appropriate to use $R^{2}$ to compare the fitting of kinetic models, but did not propose an alternative. More recent research (Wen et al. 2006; Ho 2006) also failed to put forward an improved model selection methodology. This paper applies the BIC, LILC, and AIC model selection criterion along with the $F$-test and the coefficient of determination $\left(R^{2}\right)$ to compare the relative and absolute performance of six candidate models applied to high resolution kinetic data from eight experimental systems varying in $\mathrm{pCO}_{2}$ and calcite surface area. The candidate models include the PSO, the Hill 4 and Hill 5, IPD, Power, and Elovich models. The models were fitted under the assumptions of the ordinary least-squares (OLS) fitting under the standard assumptions of error independency, normality, and constancy of variance. All experiments were carried out at the Centre for Geotechnical and Materials Modeling research laboratories at the University of Newcastle, NSW, Australia over the period 2011-2013.

\section{Materials and methods}

In this study, a series of free-drift kinetic experiments as described by Plummer et al. (1978), were undertaken to compare the ability of a range of models to characterise the kinetics of fluoride removal in the presence of granulated calcite $\left(\mathrm{CaCO}_{3}\right)$. Experimental parameters include the calcite fraction size (surface area) and the $\mathrm{CO}_{2}$ partial pressure $\left(\mathrm{pCO}_{2}\right)$, yielding a wide range of experimental dynamics. The fluoride concentration was recorded at 10 or $60 \mathrm{~s}$ intervals, yielding a high temporal resolution under controlled conditions. Prior to the start of each experiment, $400 \mathrm{~mL}$ of potassium fluoride stock solution was added to $500 \mathrm{~mL}$ polypropylene beakers, $\mathrm{pH}$ and $\mathrm{F}$ electrodes were installed and stirring was initiated. Calcite of the selected size was pre-weighed so that a constant solid liquid ratio of $33.3 \mathrm{~g} / \mathrm{L}$ was attained for each experiment. A sealed "Atmosbag" (Sigma-Aldrich) was installed around the experiment and $\mathrm{CO}_{2}$ gas was used to inflate the bag through a tube. $\mathrm{CO}_{2}$ gas is used to enhance the fluoride removal kinetics (Sleap et al. 2013) and a very slow gas flow was continued throughout the experiment to maintain positive pressure inside the "Atmosbag".

The experiments were typically allowed to run for 1-7 days, to ensure that enough time was given for the system to reach equilibrium. Calibration of the fluoride ion-selective and $\mathrm{pH}$ electrodes was routinely conducted at the start and end of each experiment. It was found that the final calibration closely matched the original values and therefore, the drift was negligible. At the start and the end of each experiment, samples were taken for ion chromatography analysis. 
With free-drift methodology, the rate of change in $\mathrm{pH}$ directly relates to the $\mathrm{CaCO}_{3}$ dissolution rate (Sun et al. 2000) and so both the fluoride concentration and $\mathrm{pH}$ data were recorded for the duration of the experiments. The experiments were undertaken in a temperature-controlled environment at $20 \pm 0.2{ }^{\circ} \mathrm{C}$. The preparation, equipment, and methodology of the experiments are described in the following sections.

Granulated calcite $\left(\mathrm{CaCO}_{3}\right)$ was used as the solid substrate in this study. Crushed limestone from a quarry (DML, Attunga, NSW) was prepared for free-drift kinetic experiments. This involved sieving into particle size fractions of $<150 \mu \mathrm{m}$ (ASTM-E11 $<100 \mathrm{mesh}$ ), 150-300 $\mu \mathrm{m}$ (100-50 mesh), 300-425 $\mu \mathrm{m} \quad$ (50-40 mesh), and 425-600 $\mu \mathrm{m}$ (40-30 mesh), rinsed with deionized water and oven dried at $40{ }^{\circ} \mathrm{C}$. Multipoint Kr-BET (Brunauer, Emmett, and Teller) sorption analysis was conducted on all size fractions, prior to the experiments using a Micromeritics Tristar 3000 to determine the surface area of the various sieved fractions. The calcite was then examined using an X-ray fluorescence analyser (Philips PW1404 wavelength dispersive sequential $\mathrm{XRF}$, with $< \pm 2 \%$ error for elemental analysis). This showed that the limestone used in these experiments was $99 \%$ pure $\mathrm{CaCO}_{3}$ with trace quantities of $\mathrm{MgO}$ (1\%), strontium (168 ppm), barium (71 ppm), zirconium (40 ppm), and other trace elements at concentrations of $<40 \mathrm{ppm}$.

The experiments were conducted in two different $\mathrm{CO}_{2}$ partial pressure environments, $\sim 10^{-0.52}$ atm $(30 \%)$ and $\sim 10^{\circ}(100 \%)$. The gas was commercially produced (BOC Scientific Gases) with certificates of analysis to ANA5024 standards and indicated errors of $\pm 0.2 \%$ or less. Overhead digital stirrers were utilised to provide highly accurate stirring rates which were logged using Lab Companion software. A stirring rate of $200 \mathrm{rpm}( \pm 0.8 \%)$ was used throughout the experimental process and checked using a stroboscope. Temperature was recorded using a DT80 datataker with $T$ type thermocouples located under each beaker. To determine the effects of the Hill sigmoidal parameter $n$ (Eqs. 9 and 10a) experiments were conducted under the exact same conditions using $<150 \mu \mathrm{m}$ only at $\mathrm{pCO}_{2} \sim 10^{-1.15}$ atm $(7 \%), \sim 10^{-1.0}$ atm $(10 \%)$, $\sim 10^{-0.52}$ atm $(30 \%), \sim 10^{-0.22}$ atm $(60 \%)$ and $\sim 10^{\circ} \mathrm{atm}(100 \%)$.

Anhydrous potassium fluoride (KF) (Sigma-Aldrich) and de-ionised (DI) water was used in the preparation of fluoride stock solutions. In all cases, the initial fluoride concentration was $2,000 \mathrm{mg} / \mathrm{L}$. The DI water was produced by a Millipore Milli-Q 185 water de-ioniser $(18.2 \mathrm{M} \Omega / \mathrm{cm})$.

Anions $\left(\mathrm{F}^{-}, \mathrm{Cl}^{-}, \mathrm{SO}_{4}^{2-}\right.$ and $\left.\mathrm{PO}_{4}^{3-}\right)$ were analysed using a Dionex ICS5000 ion chromatograph running Chromeleon 6.8 software equipped with an AS18/AG18 anion capillary/ guard columns with conductivity detection. Ion chromatography calibration standards were prepared from a Dionex Seven Anion Standard II solution by dilution with 18.2 $\mathrm{M} \Omega / \mathrm{cm}$ DI water. To optimise the ion chromatograph peak separation and resolution, all samples were syringed from the beaker and filtered using a $0.45 \mu \mathrm{m}$ nylon membrane filter (Pall-Life Sciences) and diluted with 18.2 M $\Omega$ / cm DI water.

The $\mathrm{pH}$ was measured using Orion 9165BN pH electrodes. Multipoint calibrations were completed using $\mathrm{pH} 4$, 7 and 10 NIST buffers [Orion] until a slope of between 92 and $102 \%$ of the theoretical $\mathrm{pH}$ slope (52-60 mV/decade) was achieved. Fluoride was measured with Orion 9609BN fluoride ion-selective electrodes. Multipoint calibrations were completed using 10,100,1,000, and 2,000 $\mathrm{mg} \mathrm{L}^{-1}$ of potassium fluoride made up from stock solution, until a slope of $-54 \pm 2 \mathrm{mV} /$ decade was achieved. Exact concentrations of each standard were determined by ion chromatography.

Fluoride probes were placed into the stock solutions prepared for experimentation and connected to a PC-based datalogger via ion-selective electrode pre-amplifiers. $\mathrm{CO}_{2(\mathrm{~g})}$ was then equilibrated and calcite added, fluoride removal was then recorded at either 10 or $60 \mathrm{~s}$ intervals.

The fluoride ion-selective electrode measured the activity or "effective concentration" of free fluoride ions in solution. The fluoride ion activity, $A$, is related to free fluoride ion concentration, $C_{f}$, by the activity coefficient, $\gamma_{i}$.

To correct for varying activity coefficients, all fluoride calibration standards were analysed by ion chromatography to obtain accurate fluoride concentration values. These ion chromatography concentration values were then used to determine calibration curves for the fluoride electrodes. Consequently, the problems of ionic strength effects (i.e. activity) were effectively eliminated.

All model fitting was completed with the nonlinear curve fitting Originpro 9.1 software. Model comparisons, AIC, BIC, and F-tests were also completed within Originpro 9.1. GraphPad Prism (v6.0) was also used to crosscheck Originpro 9.1 fitting and for Monte Carlo simulations. Monte Carlo simulations allow randomized Gaussian resampling of the data (based on a known standard deviation) to construct a "new" set of data.

Data from each experiment were fitted with the candidate models using GraphPad Prism (v6.0). The best fit parameters were then used to simulate a randomized resampling of the data to construct a new data set calculated from a Gaussian distribution as per Motulsky and Christopoulos (2004). The standard deviation of the residuals $\left(S_{\mathrm{yx}}\right)$ as reported from the initial model fit was used for the Monte Carlo simulations, in all cases this was not more than $\pm 0.5 \mathrm{mg} / \mathrm{g}$. For each model 1,000 Monte 
Carlo simulations were made to generate the $95 \%$ confidence intervals (CIs) for each model parameter.

\section{Results and discussion}

The Hill models minimum asymptote parameter $(D)$ were in all cases constrained to zero as unless there are predefined sources or sinks of contaminant, at $t=0 \mathrm{D}=0$ (i.e. $q_{t}=0$ ). This effectively reduces the Hill 4 model to 3 parameter, and the Hill 5 model to 4 parameter.

Knowledge of the error structure is a necessary prerequisite for the comparison of alternative mathematical models and the application of parametric statistical tests (AskelÖf et al. 1976). When the error distribution of the system is not known, the uncertainty in the values of the model parameters along with more realistic confidence intervals (CIs) can be obtained from the application of Monte Carlo computations (Motulsky and Ransnas 1987; Mishra et al. 2011). Monte Carlo computations (1,000) were done for the fastest $\left(<150 \mu \mathrm{m} ; \mathrm{pCO}_{2} \sim 100 \%\right)$ and slowest $\left(425-600 \mu \mathrm{m} ; \mathrm{pCO}_{2} \sim 30 \%\right)$ experiments for all six candidate models. Table 1 shows the upper and lower $95 \%$ CIs generated from 1,000 Monte Carlo computations for the PSO, Hill 4 and Hill 5 models only. Analysis of the simulations shows that in all cases the observed data (Figs. 1, 2) fall within the Hill $595 \%$ CIs supporting the assumptions of error independency, normality, and constancy of variance. This is not surprising as the error structure is not likely to affect modelling conclusions to

Table 1 Monte Carlo $95 \%$ confidence intervals for the kinetically fastest and slowest calcite/fluoride experiments

\begin{tabular}{|c|c|c|c|c|c|c|c|c|c|c|c|}
\hline \multirow[t]{2}{*}{ Calcite fraction $(\mu \mathrm{m})$} & \multirow[t]{2}{*}{$\mathrm{pCO}_{2}(\%)$} & \multicolumn{3}{|l|}{ PSO } & \multicolumn{3}{|l|}{ Hill 4} & \multicolumn{4}{|l|}{ Hill 5} \\
\hline & & $95 \% \mathrm{CI}^{*}$ & $k_{\mathrm{pso}}\left(\times 10^{-4}\right)$ & $q_{\mathrm{e}}$ & $A$ & $k_{\mathrm{Hill4}}$ & $n$ & $\bar{A}$ & $E$ & $k_{\mathrm{Hill5}}$ & $n$ \\
\hline \multirow[t]{2}{*}{$<150 \mu \mathrm{m}$} & 100 & $U$ & 48.476 & 59.523 & 59.354 & 5.214 & 1.543 & 59.333 & 0.505 & 9.213 & 1.836 \\
\hline & & $L$ & 50.074 & 59.577 & 59.366 & 5.251 & 1.555 & 59.348 & 0.531 & 9.698 & 1.864 \\
\hline \multirow[t]{2}{*}{$425-600 \mu \mathrm{m}$} & 30 & $U$ & 1.018 & 57.081 & 61.836 & 202.942 & 0.841 & 59.003 & 0.688 & 275.744 & 0.965 \\
\hline & & $L$ & 1.033 & 57.245 & 62.271 & 206.852 & 0.852 & 59.850 & 0.777 & 315.926 & 1.028 \\
\hline
\end{tabular}

* $U$ is upper $95 \% \mathrm{CI}$; $L$ is lower $95 \% \mathrm{CI}$
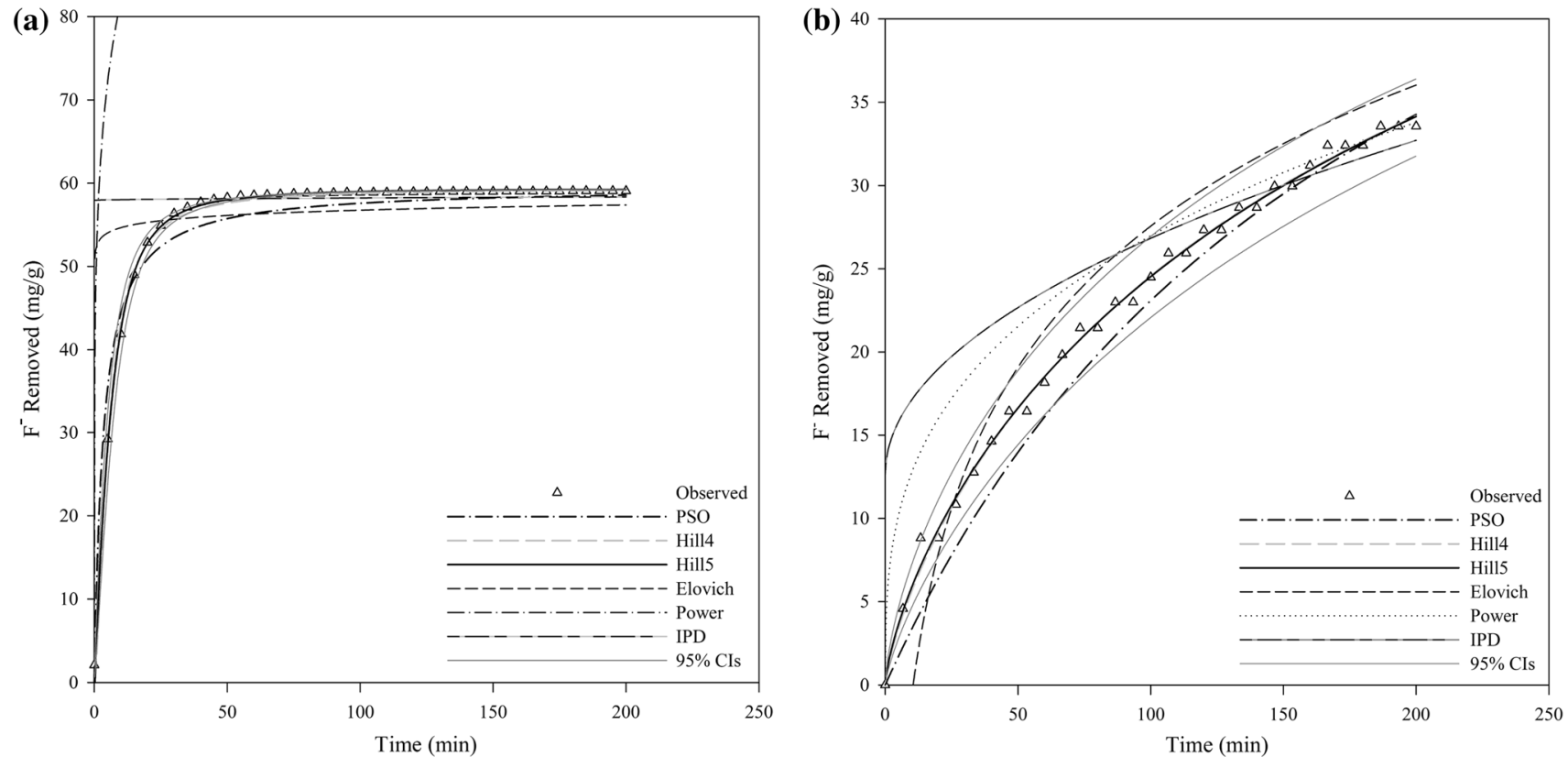

Fig. 1 Comparison of observed and modelled data for $\mathrm{pCO}_{2} \sim 100 \%$ experiments with Hill $595 \%$ confidence intervals $(\mathrm{CIs})$. a $<150 \mu \mathrm{m}$ calcite; b $425-600 \mu \mathrm{m}$ calcite 

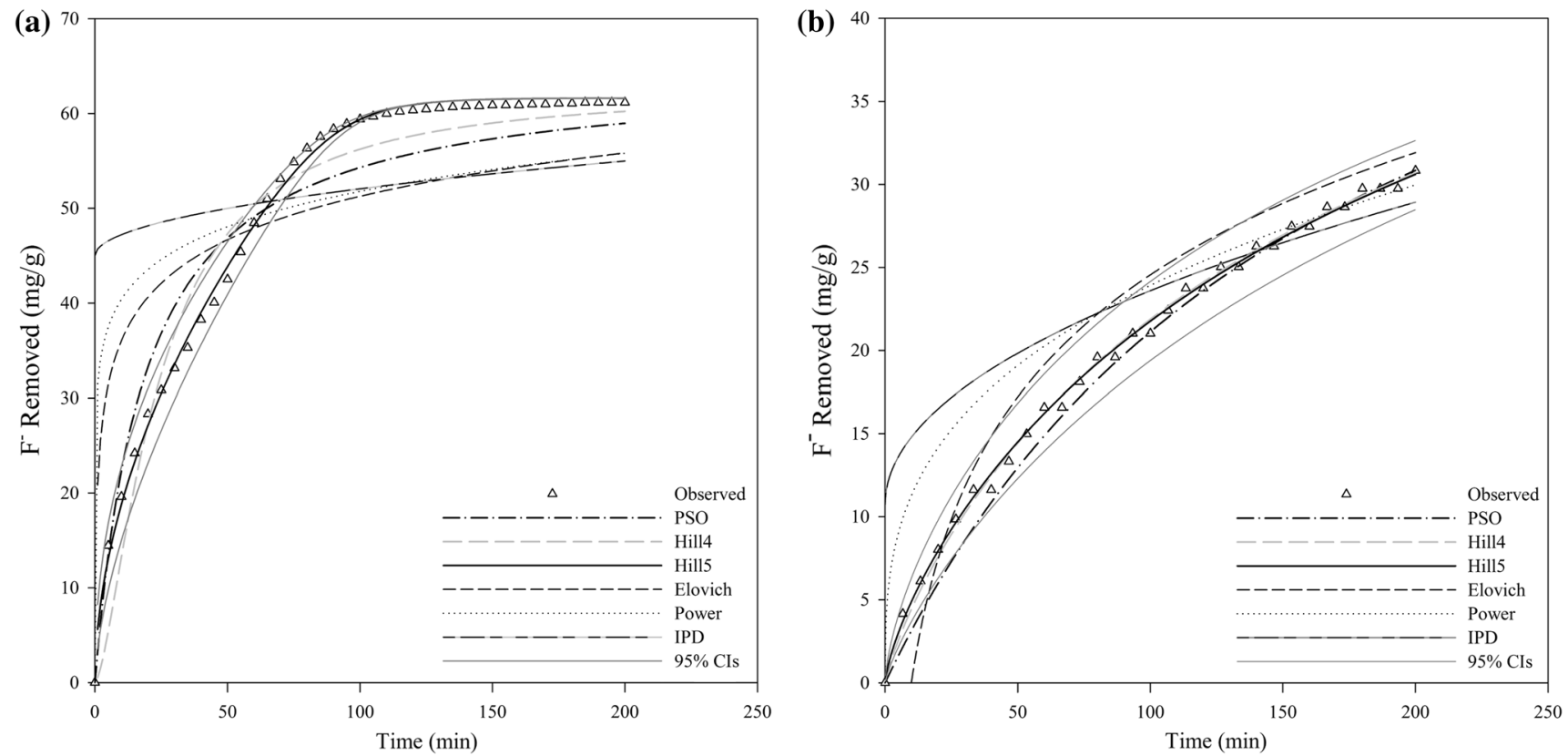

Fig. 2 Comparison of observed and modelled data for $\mathrm{pCO}_{2} \sim 30 \%$ experiments with Hill $595 \%$ confidence intervals (CIs). a $<150 \mu \mathrm{m}$ calcite; b $425-600 \mu \mathrm{m}$ calcite

Table 2 Least-squares fitted parameter values for Power, IPD, and Elovich models

\begin{tabular}{|c|c|c|c|c|c|c|c|c|c|c|}
\hline \multirow[t]{2}{*}{ Calcite fraction $(\mu \mathrm{m})$} & \multirow[t]{2}{*}{$\mathrm{pCO}_{2}(\%)$} & \multicolumn{3}{|l|}{ Power } & \multicolumn{3}{|l|}{ IPD } & \multicolumn{3}{|l|}{ Elovich } \\
\hline & & $a$ & $b$ & $R^{2}$ & $\bar{C}$ & $a$ & $R^{2}$ & $\alpha$ & $\beta$ & $R^{2}$ \\
\hline$<150$ & 100 & 53.6 & 0.013 & 0.182 & 57.92 & 0.03 & 0.054 & 1.31 & 0.013 & 0.163 \\
\hline $150-300$ & 100 & 11.8 & 0.228 & 0.919 & 22.87 & 1.08 & 0.822 & 2.82 & 0.100 & 0.971 \\
\hline $300-425$ & 100 & 10.03 & 0.247 & 0.943 & 20.12 & 1.13 & 0.866 & 2.21 & 0.098 & 0.981 \\
\hline $425-600$ & 100 & 6.05 & 0.325 & 0.973 & 12.63 & 1.42 & 0.938 & 1.16 & 0.082 & 0.972 \\
\hline$<150$ & 30 & 31.54 & 0.108 & 0.624 & 45.00 & 0.708 & 0.388 & 154.34 & 0.151 & 0.695 \\
\hline $150-300$ & 30 & 10.63 & 0.223 & 0.917 & 20.08 & 0.95 & 0.816 & 2.87 & 0.119 & 0.968 \\
\hline $300-425$ & 30 & 7.90 & 0.222 & 0.964 & 15.942 & 1.16 & 0.907 & 1.76 & 0.102 & 0.981 \\
\hline $425-600$ & 30 & 5.35 & 0.325 & 0.965 & 10.74 & 1.29 & 0.928 & 1.07 & 0.094 & 0.972 \\
\hline
\end{tabular}

* $h=k_{p s o} q_{e}^{2}$

any large extent given the number of data points $(\sim 7,800)$ in each experiment. In addition, visual inspection of the kinetics shows that the Hill 5 model has exceptional ability to fit rapid (Fig. 1a) and/or asymmetric (Fig. 2a) data with the $95 \%$ CIs for the Hill 5 model also shown.

Model selection: least squared $\left(R^{2}\right)$ fitting and $F$-tests

Figures 1 and 2 compare the observed data to the modelled results only for the highest $(<150 \mu \mathrm{m})$ and lowest
(425-600 $\mu \mathrm{m})$ surface area calcite fractions at each $\mathrm{pCO}_{2}$ with all other results falling between. Modelling was completed on the full data set; however, the curves have been truncated to the first $200 \mathrm{~min}$ to enable clearer examination of the early part of the removal curves.

The least-squares fitted parameters are shown in Tables 2 and 3. The results show that the Power, IPD, or Elovich (Table 2) models, in general, have a good $R^{2}$ $(>0.9)$. However, these models appear to be unable to cope with rapid kinetics. In particular, the $R^{2}$ decreases sharply 
Table 3 Least-squares fitted parameter values for PSO, Hill 4 and Hill 5 parameter models

\begin{tabular}{|c|c|c|c|c|c|c|c|c|c|c|c|c|c|c|}
\hline \multirow[t]{2}{*}{ Calcite fraction $(\mu \mathrm{m})$} & \multirow[t]{2}{*}{$\mathrm{pCO}_{2}(\%)$} & \multicolumn{4}{|l|}{ PSO } & \multicolumn{4}{|c|}{ Hill (4 parameter) } & \multicolumn{5}{|c|}{ Hill (5 parameter) } \\
\hline & & $h^{*}$ & $k_{\mathrm{pso}}\left(\times 10^{-4}\right)$ & $q_{\mathrm{e}}$ & $R^{2}$ & $A$ & $k$ & $n$ & $R^{2}$ & $A$ & $E$ & $k$ & $n$ & $R^{2}$ \\
\hline$<150$ & 100 & 17.5 & 49.2 & 59.6 & 0.936 & 59.4 & 5.2 & 1.5 & 0.996 & 59.3 & 0.5 & 9.5 & 1.8 & 0.998 \\
\hline $150-300$ & 100 & 0.7 & 1.8 & 60.2 & 0.997 & 62.2 & 93.9 & 0.9 & 0.998 & 60.4 & 0.6 & 169.4 & 1.1 & 0.999 \\
\hline $300-425$ & 100 & 0.6 & 1.6 & 59.8 & 0.995 & 64.0 & 120.1 & 0.8 & 0.999 & 61.9 & 0.7 & 201.1 & 1.0 & 1.000 \\
\hline $425-600$ & 100 & 0.4 & 0.8 & 66.5 & 0.994 & 76.2 & 260.5 & 0.8 & 0.999 & 74.2 & 0.9 & 318.6 & 0.8 & 0.999 \\
\hline$<150$ & 30 & 3.4 & 48.2 & 64.5 & 0.934 & 62.6 & 23.7 & 1.5 & 0.964 & 61.6 & 0.1 & 95.4 & 7.5 & 0.997 \\
\hline $150-300$ & 30 & 0.7 & 2.5 & 51.3 & 0.996 & 52.9 & 81.9 & 0.9 & 0.998 & 50.6 & 0.5 & 196.2 & 1.2 & 0.999 \\
\hline $300-425$ & 30 & 0.5 & 1.5 & 55.8 & 0.991 & 63.7 & 158.9 & 0.7 & 0.999 & 59.5 & 0.6 & 306.0 & 1.0 & 0.999 \\
\hline $425-600$ & 30 & 0.3 & 1.0 & 57.2 & 0.997 & 62.0 & 204.9 & 0.8 & 0.999 & 59.4 & 0.7 & 296.6 & 1.0 & 0.999 \\
\hline
\end{tabular}

Note the minimum asymptote for the Hill 4 and Hill 5 models was constrained to zero

Table 4 Model selection criterion results for $\mathrm{pCO}_{2} \sim 100 \%$ experiments

\begin{tabular}{|c|c|c|c|c|c|c|c|c|c|}
\hline Experiment & Model & $N$ & $p$ & $R^{2}$ & RSS & $\mathrm{BIC}$ & LILC & AIC & Rank \\
\hline \multirow[t]{6}{*}{$<150 \mu \mathrm{m}$} & PSO & 23,786 & 2 & 0.936 & $5,565.4$ & $-34,519.8$ & $-15,003.6$ & $-34,544.0$ & 3 \\
\hline & Hill 4 & 23,786 & 3 & 0.996 & 271.0 & $-106,383.3$ & $-46,221.7$ & $106,423.7$ & 2 \\
\hline & Hill 5 & 23,786 & 4 & 0.998 & 172.5 & $-117,121.2$ & $-50,888.8$ & $117,169.6$ & 1 \\
\hline & Elovich & 23,786 & 2 & 0.163 & $68,328.3$ & $25,129.9$ & $10,901.9$ & $25,105.6$ & 4 \\
\hline & Power & 23,786 & 2 & 0.182 & $68,837.7$ & $25,306.5$ & $10,978.6$ & $25,282.3$ & 5 \\
\hline & IPD & 23,786 & 2 & 0.054 & $82,743.8$ & $29,683.1$ & $12,879.4$ & $29,658.9$ & 6 \\
\hline \multirow[t]{6}{*}{$150-300 \mu \mathrm{m}$} & PSO & 7,684 & 2 & 0.997 & $2,437.4$ & $-8,796.1$ & $-1,075.3$ & $-8,816.9$ & 3 \\
\hline & Hill 4 & 7,684 & 3 & 0.998 & $1,186.6$ & $-14,309.3$ & $-11,159.8$ & $-14,344.0$ & 2 \\
\hline & Hill 5 & 7,684 & 4 & 0.999 & $1,069.0$ & $-15,111.2$ & $-12,667.1$ & $-15,146.0$ & 1 \\
\hline & Elovich & 7,684 & 2 & 0.971 & $22,651.1$ & $8,333.8$ & $7,293.4$ & $8,312.9$ & 4 \\
\hline & Power & 7,684 & 2 & 0.919 & $62,752.5$ & $16,163.7$ & $7,318.2$ & $16,142.8$ & 5 \\
\hline & IPD & 7,684 & 2 & 0.822 & $139,331.2$ & $22,292.9$ & $7,932.2$ & $22,272.0$ & 6 \\
\hline \multirow[t]{6}{*}{$300-425 \mu \mathrm{m}$} & PSO & 7,686 & 2 & 0.995 & $3,942.2$ & $-5,104.9$ & $-2,227.5$ & $-5,125.7$ & 3 \\
\hline & Hill 4 & 7,686 & 3 & 0.999 & 362.0 & $-23,439.0$ & $-10,197.1$ & $-23,473.7$ & 2 \\
\hline & Hill 5 & 7,686 & 4 & 1.000 & 317.7 & $-24,444.0$ & $-10,633.0$ & $-24,478.7$ & 1 \\
\hline & Elovich & 7,686 & 2 & 0.981 & $15,661.4$ & $5,497.7$ & $2,377.1$ & $5,476.9$ & 4 \\
\hline & Power & 7,686 & 2 & 0.943 & $45,316.1$ & $13,663.8$ & $5,923.6$ & $13,643.0$ & 5 \\
\hline & IPD & 7,686 & 2 & 0.866 & $108,553.1$ & $20,378.1$ & $8,839.6$ & $20,357.3$ & 6 \\
\hline \multirow[t]{6}{*}{$425-600 \mu \mathrm{m}$} & PSO & 7,686 & 2 & 0.994 & $6,644.6$ & $-1,092.2$ & -484.8 & $-1,113.1$ & 3 \\
\hline & Hill 4 & 7,686 & 3 & 0.999 & 684.4 & $-18,554.1$ & $-8,071.7$ & $-18,581.9$ & 2 \\
\hline & Hill 5 & 7,686 & 4 & 0.999 & 666.8 & $-18,744.7$ & $-8,157.8$ & $-18,779.4$ & 1 \\
\hline & Elovich & 7,686 & 2 & 0.972 & $32,448.8$ & $11,096.7$ & $4,808.8$ & $11,075.9$ & 5 \\
\hline & Power & 7,686 & 2 & 0.973 & $31,939.9$ & $10,975.2$ & $4,756.0$ & $10,954.4$ & 4 \\
\hline & IPD & 7,686 & 2 & 0.938 & $72,896.0$ & $17,317.5$ & $7,510.4$ & $17,296.7$ & 6 \\
\hline
\end{tabular}

$N$ is the number of data points, $p$ is the number of parameters. Note: values between criterion cannot be compared

for the fastest reactions $(<150 \mu \mathrm{m}$ fraction) as determined by the instantaneous sorption rate $h_{\text {pso }}$ (Table 3 ) with all $R^{2}<0.182$.

For the nested models PSO, Hill 4 and Hill 5 (Table 3) the $R^{2}$ values for the Hill models, superficially indicate a better fit than the PSO, which is not surprising given that the increase in the number of parameters automatically implies a better fit from the $R^{2}$ fitting method (Johnson and Omland 2004). When the $R^{2}$ of nested models are close, the statistical $F$-test (Eq. 1.) allows a comparison to determine 
Table 5 Model selection criterion results for $\mathrm{pCO}_{2} \sim 30 \%$ experiments. $N$ is the number of data points, $p$ is the number of parameters. Note: values between criterion cannot be compared

\begin{tabular}{|c|c|c|c|c|c|c|c|c|c|}
\hline Experiment & Model & $N$ & $p$ & $R^{2}$ & RSS & BIC & LILC & AIC & Rank \\
\hline \multirow[t]{6}{*}{$<150 \mu \mathrm{m}$} & PSO & 924 & 2 & 0.934 & $4,059.0$ & $1,388.0$ & 594.8 & $1,373.5$ & 3 \\
\hline & Hill 4 & 924 & 3 & 0.964 & $2,183.2$ & 821.8 & 346.5 & 802.5 & 2 \\
\hline & Hill 5 & 924 & 4 & 0.997 & 161.9 & $-1,575.0$ & $-2,739.5$ & $-1,599.1$ & 1 \\
\hline & Elovich & 924 & 2 & 0.695 & $18,734.2$ & $2,801.2$ & $1,208.6$ & $2,786.7$ & 4 \\
\hline & Power & 924 & 2 & 0.624 & $23,029.4$ & $2,991.9$ & $1,291.4$ & $2,977.4$ & 5 \\
\hline & IPD & 924 & 2 & 0.388 & $37,498.7$ & $3,442.4$ & $1,487.1$ & $3,427.9$ & 6 \\
\hline \multirow[t]{6}{*}{$150-300 \mu \mathrm{m}$} & PSO & 6,977 & 2 & 0.996 & $1,910.3$ & $-9,011.2$ & $-3,923.9$ & $-9,031.7$ & 3 \\
\hline & Hill 4 & 6,977 & 3 & 0.998 & $1,094.6$ & $-12,887.9$ & $-5,610.8$ & $-12,915.3$ & 2 \\
\hline & Hill 5 & 6,977 & 4 & 0.999 & 649.1 & $-16,524.8$ & $-26,818.9$ & $-16,559.0$ & 1 \\
\hline & Elovich & 6,977 & 2 & 0.968 & $15,774.3$ & $5,718.1$ & $2,473.0$ & $5,697.6$ & 4 \\
\hline & Power & 6,977 & 2 & 0.917 & $41,584.6$ & $12,481.3$ & $5,410.2$ & $12,460.7$ & 5 \\
\hline & IPD & 6,977 & 2 & 0.816 & $92,526.5$ & $18,061.2$ & $7,833.5$ & $18,040.7$ & 6 \\
\hline \multirow[t]{6}{*}{$300-425 \mu \mathrm{m}$} & PSO & 5,977 & 2 & 0.991 & $6,273.6$ & -714.8 & 126.9 & -735.4 & 3 \\
\hline & Hill 4 & 5,977 & 3 & 0.999 & 509.7 & $-18,220.6$ & $-6,388.8$ & $-18,248.0$ & 2 \\
\hline & Hill 5 & 5,977 & 4 & 0.999 & 354.5 & $-20,745.6$ & $-7,331.0$ & $-20,779.9$ & 1 \\
\hline & Elovich & 5,977 & 2 & 0.981 & $12,550.7$ & $4,123.1$ & $1,926.8$ & $4,102.6$ & 4 \\
\hline & Power & 5,977 & 2 & 0.964 & $24,032.6$ & $8,655.7$ & $3,613.2$ & $8,635.1$ & 5 \\
\hline & IPD & 5,977 & 2 & 0.907 & $62,447.4$ & $15,318.1$ & $6,091.9$ & $15,297.5$ & 6 \\
\hline \multirow[t]{6}{*}{$425-600 \mu \mathrm{m}$} & PSO & 6,976 & 2 & 0.997 & $2,443.1$ & $-7,292.9$ & $-3,177.6$ & $-7,313.4$ & 3 \\
\hline & Hill 4 & 6,976 & 3 & 0.999 & 644.6 & $-16,578.6$ & $-7,213.6$ & $-16,606.0$ & 2 \\
\hline & Hill 5 & 6,976 & 4 & 0.999 & 580.1 & $-17,305.6$ & $-7,532.6$ & $-17,339.9$ & 1 \\
\hline & Elovich & 6,976 & 2 & 0.972 & $22,673.8$ & $8,249.4$ & $3,572.3$ & $8,228.8$ & 4 \\
\hline & Power & 6,976 & 2 & 0.965 & $28,029.7$ & $9,728.7$ & $4,214.8$ & $9,708.1$ & 5 \\
\hline & IPD & 6,976 & 2 & 0.928 & $58,179.7$ & $14,823.1$ & $6,427.2$ & $14,802.5$ & 6 \\
\hline
\end{tabular}

which model one actually fits better. Tables 4 and 5 define all the parameters required to calculate the $F$-test using Eq. 1 .

Comparison of the Hill 4 and Hill 5 models to the PSO model (the null hypothesis) in all cases give a statistically highly significant result $(p<0.001)$ at the traditional $5 \%$ significance level, indicating that the PSO model can be rejected and that the data are best described by the Hill 5 parameter model. For example, the kinetically fastest experiments using $<150 \mu \mathrm{m}$ calcite at $\mathrm{pCO}_{2} \sim 100 \%$ (Table 4) gave $\mathrm{F}(\mathrm{PSO}$, Hill 4) $=464,637.3, p<0.001$ and $F(\mathrm{PSO}$, Hill 5$)=371,750.6 ; p<0.001$. Setting the Hill 4 model as the null hypothesis, the Hill 5 model also showed a statistically highly significant result with the Hill 5 parameter model favoured over the Hill 4 parameter model with $\mathrm{F}($ Hill 4 , Hill 5) $=13,579.9 .4 ; p<0.001$. In all cases, the $F$-test results indicate that, in comparison to the Hill 4 or Hill 5 models at the traditional $5 \%$ significance level, there is zero chance of obtaining results that fit significantly better using the PSO. Similarly, the Hill 5 should be the model of choice based on the $F$-test as it is statistically superior in the order Hill $5>$ Hill $4>$ PSO.

Model selection: information criterion tests

When comparisons between non-nested models are required, information criterion tests can be used. Data shown in Tables 4 and 5 were used to calculate the information criterion for the AIC, BIC, and LILC using Eqs. 2-4, respectively. For each experiment, Tables 4 and 5 show the raw information criterion results with the most negative value for the respective information criterion the "best" model. In seven out the eight experiments, every information criterion ranked the models in the order Hill 5, Hill 4, PSO, Elovich, Power, and IPD. However, in the $425-600 \mu \mathrm{m}$ calcite fraction at pCO2 $\sim 100 \%$ (Table 4), the order was Hill 5, Hill 4, PSO, Power, Elovich and IPD. Consequently, the Hill 5 model 
Table 6 Information criterion (AIC, BIC, LILC) weight and evidence ratio (ER) results for $425-600 \mu \mathrm{m}$ calcite at $\mathrm{pCO}_{2} \sim 100 \%$

\begin{tabular}{llllllllll}
\hline & $\Delta$ AIC & \multirow{2}{*}{$w_{i}$ (AIC) } & $\begin{array}{l}E R \\
\text { AIC }\end{array}$ & $\Delta$ LILC & $w_{i}($ LILC) & $\begin{array}{l}E R \\
\text { LILC }\end{array}$ & $\Delta$ BIC & $w_{i}$ (BIC) & $\begin{array}{l}E R \\
\text { BIC }\end{array}$ \\
\hline PSO & $10,026.5$ & 0 & - & 4,355 & 0 & - & $10,012.7$ & 0 \\
Hill 4 & 733.9 & $4.3 \times 10^{-160}$ & $2.3 \times 10^{159}$ & 319 & $5.4 \times 10^{-70}$ & $1.9 \times 10^{69}$ & 727 & $1.4 \times 10^{-158}$ & $7.3 \times 10^{157}$ \\
Hill 5 & 0 & 1 & 1 & 0 & 1 & 1 & 0 & 1 & 1 \\
Elovich & $25,568.7$ & 0 & - & $11,104.9$ & 0 & - & 25,555 & 0 & - \\
Power & 27,048 & 0 & - & $11,747.4$ & 0 & - & $27,034.3$ & 0 \\
IPD & $32,142.4$ & 0 & - & $13,959.8$ & 0 & - & $32,128.7$ & 0 \\
\hline
\end{tabular}

$\Delta \mathrm{IC}=\left(\mathrm{IC}_{i}-\mathrm{IC}_{\text {miu }}\right)$ see Eq. $5 \mathrm{~b}$

is the "best" model for fitting the data under the conditions described.

As the raw information criterion data are often difficult to interpret (Wagenmakers and Farrell 2004), the relative weights for each model criterion (Eq. 5a) or the evidence ratio (Eq. 6) can be calculated. In addition, the BIC can also be used to calculate a BF (Eq. 7) for each model. These methods give an indication of the relative strength of the evidence for favouring one model over another. Table 6 shows an example of one experiment (425-600 $\mu \mathrm{m}$ calcite, $\mathrm{pCO}_{2} \sim 100 \%$ ) where the model strength of evidence has been calculated from the raw information criterion (Table 2). The BF has been left out as this is equivalent to the evidence ratio (ER) and the inverse of the relative weight $\left(w_{i}\right)$. It is clear that the Hill 5 model is without a doubt the most strongly favoured over all other tested models having evidence ratios of $2.3 \times 10^{159}$ (AIC), $1.8 \times 10^{69}$ (LILC), and $7.3 \times 10^{157}$ (BIC) times that of the closest (Hill 4) model. This in effect gives the Hill 5 model a probability of $>99.99 \%$ of being the "best" model. Analysis of all other experiments also confirms this finding (not shown). All other models (PSO, etc.) have such a large $\triangle \mathrm{IC}$ that their relative weight approaches zero and consequently the respective evidence ratio, being $1 /$ relative weight, therefore approaches infinity (undefinable). In addition in every experiment, $\Delta \mathrm{BIC}$ is $>150$ and accordingly the evidence is "very strong" that the Hill 5 model is the "best" model of those tested (Kass and Raftery 1995).

The Hill equation as a mechanistic model

Hill model parameters are generally only empirical in nature and therefore have no mechanistic meaning. In this section, we derive physical meanings for the parameters of the Hill model through unit analysis and comparison with the well-established parameters of the PSO model.

Table 7 shows the parameters for the PSO model, the comparable Hill 4 and Hill 5 parameters and their respective units. The PSO initial sorption rate, $h_{\text {pso }}$ ( $\mathrm{mg} \mathrm{g}^{-1} \min ^{-1}$ ) can be shown to be dimensionally equivalent to a parameter we define as the Hill initial sorption rate $h_{\text {Hill }}$ where:

$h_{\mathrm{Hill4}}=\frac{A-D}{k_{\mathrm{Hill} 4}}$

$h_{\text {Hill5 }}=\mathrm{TA}^{2}$

As the Hill equation already includes the parameter $k$ (min), we define a new parameter, $T$ (the Turner parameter), which is dimensionally equivalent to the Pseudo-Second-Order rate constant, $k_{\mathrm{pso}}\left(\mathrm{g} \mathrm{mg}^{-1} \mathrm{~min}^{-1}\right)$. Equations 19 and 20 define $T$ for the Hill 4 and Hill 5 models, respectively.

$T=\frac{h_{\text {Hill4 }}}{(A-D)^{2}}=\frac{1}{k_{\text {Hill4 }}(A-D)}$

$T=\frac{1}{t_{0.5}(A-D)}$

where $t_{0.5}$ is given by Eq. $10 \mathrm{~b}$.

To prove the above relationships, the data were fitted by the PSO, Hill 4 and Hill 5 models and Eqs. 17-20 applied. Figure 3a shows the Hill and PSO model results of the $\mathrm{pCO}_{2} \sim 30 \%$ experiments (Table 3) and compares the derived $T$ parameter to the corresponding $k_{\text {pso }}$ parameter. It is evident that the newly defined $T$ parameter closely matches the respective $k_{\text {pso }}$ parameter with the differences attributed to better fitting of the data by the Hill models as supported by the $F$-test, AIC, BIC, and LILC calculations. 
Table 7 Pseudo-second order (PSO) and Hill model parameter unit comparison

\begin{tabular}{|c|c|c|c|c|c|}
\hline Description & PSO parameter & Units & Hill 4 parameter ${ }^{*}$ & Hill 5 parameter & Units \\
\hline Sorption rate & $h_{\mathrm{pso}}$ & $\mathrm{mg} \mathrm{g}^{-1} \min ^{-1}$ & $h_{\mathrm{Hill} 4}=\frac{(A-D)}{k_{\mathrm{Hill}} 4}$ & $h_{\mathrm{Hill5}}=\mathrm{TA}^{2}$ & $\mathrm{mg} \mathrm{g}^{-1} \min ^{-1}$ \\
\hline Reaction half-life & $t_{0.5}=\frac{1}{k_{\mathrm{pso}} q_{\mathrm{e}}}$ & $\min$ & $t_{0.5}=k_{\mathrm{Hill} 4}$ & $t_{0.5}=k_{\mathrm{Hill}}\left(\left(2^{\frac{1}{E}}-1\right)^{\left(\frac{-1}{n}\right)}\right.$ & $\min$ \\
\hline Rate constant & $k_{\mathrm{pso}}=\frac{h_{\mathrm{pso}}}{q_{\mathrm{e}}^{2}}$ & $\mathrm{~g} \mathrm{mg}^{-1} \min ^{-1}$ & $T=\frac{1}{k_{\text {Hill }}(A-D)}$ & $T=\frac{1}{t_{0.5}(A-D)}$ & $\mathrm{g} \mathrm{mg}^{-1} \min ^{-1}$ \\
\hline Equilibrium sorption capacity & $q_{\mathrm{e}}$ & $\mathrm{mg} \mathrm{g}^{-1}$ & $A^{* *}, D$ & $A, D$ & $\mathrm{mg} \mathrm{g}^{-1}$ \\
\hline
\end{tabular}

* $k_{\mathrm{Hill}}$ has units of time $(\min )$
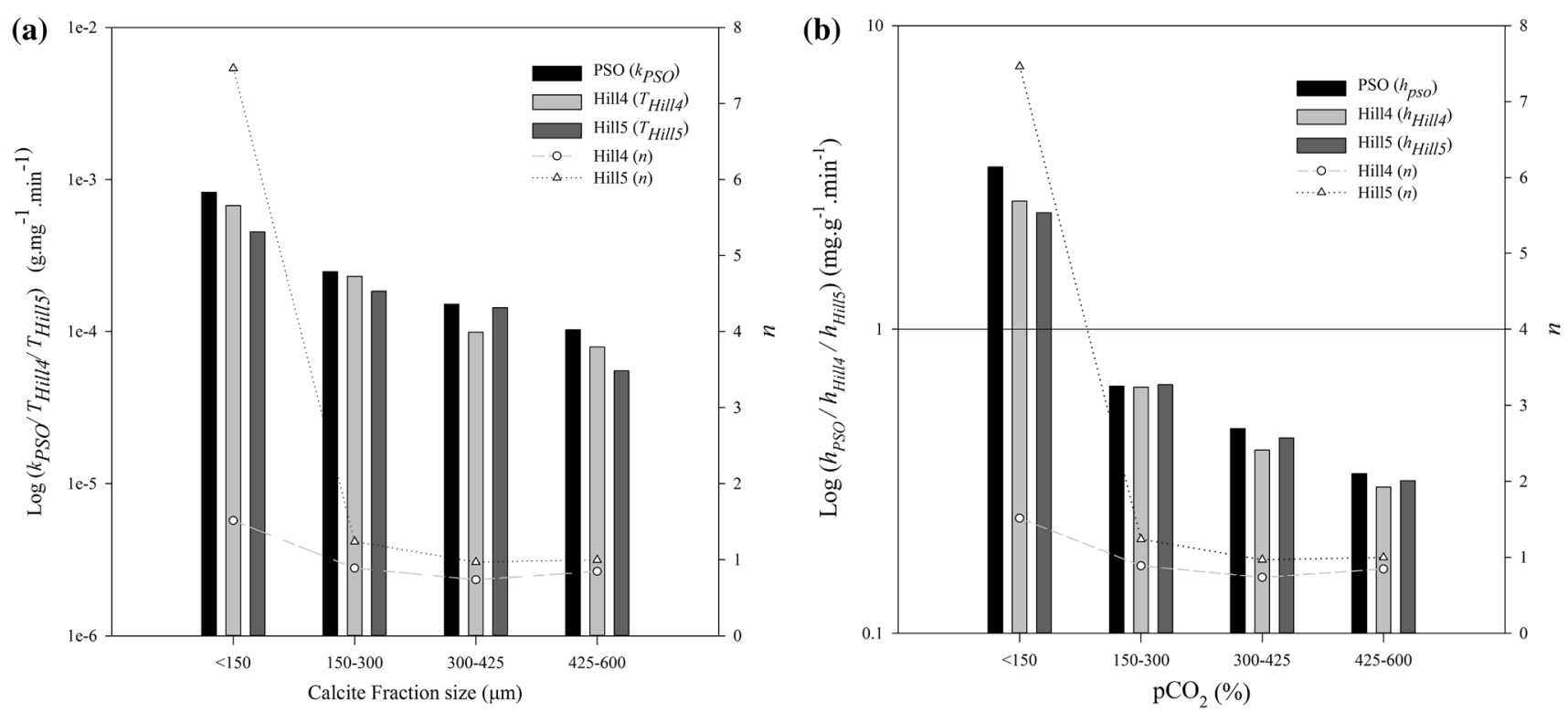

Fig. 3 The influence of the Hill sigmoidal parameter, $n$ on (a) model reaction rate constants $k_{\mathrm{pso}}, T_{\mathrm{Hill}}$, and $T_{\mathrm{Hill}}$; $\mathbf{b}$ Instantaneous sorption $h_{\mathrm{pso}}$, $h_{\mathrm{Hill}}$, and $h_{\mathrm{Hill}}$. For experimental data $\mathrm{pCO}_{2} \sim 30 \%$ (see Table 3 for further detail)

The $T$ parameter, and therefore its comparison to $k_{\mathrm{Hill}}$, is not affected by changes in the Hill parameter $n$. For example, it can be seen (Fig. 3a) that as $n$ increases the comparison of $T$ to $k_{\text {pso }}$ remain very close indicating that Eqs. 19 and 20 are independent of $n$ with variations once again due to poor fitting of the PSO model as indicated by $F$-test, AIC, BIC, and LILC calculations (Table 5).

Application of Eqs. 17 and 18 to the experimental data allows a comparison of the instantaneous sorption rates $\left(h_{\mathrm{Hill}}\right.$ and $\left.h_{\mathrm{pso}}\right)$. For example, the experiment using $\mathrm{pCO}_{2}$ $\sim 30 \% ;<150 \mu \mathrm{m}$ calcite, $h_{\text {pso }} \sim 3.4$ with $h_{\mathrm{Hill}} \sim 2.7$ and $h_{\text {Hills }} \sim 2.4$. However, the experiment using $\mathrm{pCO}_{2}$ $\sim 100 \% ; 150-300 \mu \mathrm{m}$ calcite results in $h_{\mathrm{pso}} \sim 0.80$ and $h_{\text {Hill }} \sim 0.76$. Consequently, it appears that smaller sized fractions (e.g. $<150 \mu \mathrm{m}$ ) show the largest difference due to the apparent inability of the PSO model to fit systems undergoing rapid kinetic processes. The poorer fitting of the PSO model (Figs. 1a, 2a) is therefore attributed to the increased dissolution rate of the higher surface area calcite. Similar results are obtained for the $\mathrm{pCO}_{2} \sim 100 \%$ experiments (not shown), with comparable $T$ and $k_{\text {pso }} ; h_{\text {Hill }}$ and

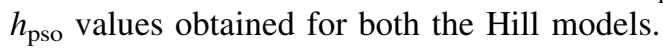

Figure 3a also shows an apparent large discrepancy in $n$ for the $<150 \mu \mathrm{m}$ calcite fractions. However, this is a function of the superior fitting of the Hill 5 model due to the asymmetry parameter $(E)$. The addition of the 
$E$ parameter allows the Hill model to reproduce the asymmetry in the observed data (Gottschalk and Dunn 2005; Giraldo et al. 2002). Figure $3 \mathrm{a}\left(\mathrm{pCO}_{2}=30 \%\right.$, calcite fraction $<150 \mu \mathrm{m}$ ) provides an interesting comparison of the models as this system shows significant asymmetry in the observed sorption curve. It is clear that the Hill 5 model outperforms all other models for this experiment as seen by the superior fit to the observed data (Fig. 1a) and the much lower BIC, LILC and AIC values (Table 5) as well as the $F$-test as detailed above. Consequently, neither the Hill parameter $n$, which represents the shape (sigmoidicity) of the kinetics curve, nor the asymmetry factor $E$, affects the derived $T$ and $h$ parameter analogy with the PSO model.

\section{Conclusion}

This study undertook a formal model selection procedure based on the BIC, LILC, AIC, sum-of-squares $F$-test, in combination with the coefficient of determination $\left(R^{2}\right)$ for a range of candidate kinetics sorption models. The candidate models were as follows: the PSO, Hill 4 and Hill 5, IPD, Power, and the Elovich models. This study has emphasised the importance of incorporating the number of parameters into the model selection procedures. Previous studies have used only the $R^{2}$ for model evaluation and selection; however, this is not a statistically robust approach and can be prone to over-fitting. The $R^{2}$ value can be used to ensure goodness-of-fit of a particular model to a particular set of data; however, a measure that incorporates the number of model parameters, such as the $F$-test for nested models, and the BIC, LILC, AIC for all models is necessary to undertake reliable model selection.

Even though the AIC is considered not to be a "consistent" information criterion unlike the BIC or LILC (Foubert et al. 2002; Wagenmakers and Farrell 2004; Stone 2005), the results presented show that AIC and BIC all predict the "best" model rankings in the same order and demonstrate that the order of superiority of models for fitting the data was Hill $5>$ Hill $4>$ PSO $>$ Elovich $>$ Power $>$ IPD. This was also supported by all other model fitting tests along with the evidence ratios, information criterion weights and BFs.

Unit and numerical analysis between the Hill and PSO models has shown that parameters of the Hill model have a physical mechanistic meaning and that the newly defined $T$ parameter of the Hill models is equivalent to the pseudosecond-order rate constant $\left(k_{\mathrm{pso}}\right)$. Similarly, it has been shown that PSO instantaneous sorption coefficient, $h_{\mathrm{pso}}$, can also be obtained from fitted Hill model parameters with very good agreement. In the field of geochemistry, the use of the four and five parameter Hill models for describing sorption kinetics has been overlooked with many studies favouring the PSO model. It is strongly recommended that the Hill model be considered more widely as a general predictive tool in geochemistry.

Acknowledgments This research was funded by Australian Research Council Linkage Grant LP100200488 in conjunction with Hydro Aluminium Kurri Kurri, New South Wales, Australia.

\section{References}

Akaike H (1974) A new look at the statistical model identification. IEEE Trans Automat Contr 19:716-723

Asci Y, Acikel U, Acikel YS (2012) Equilibrium, hysteresis and kinetics of cadmium desorption from sodium-feldspar using rhamnolipid biosurfactant. Environ Technol 33(16):1857-1868

AskelÖf P, Korsfeldt M, Mannervik B (1976) Error structure of enzyme kinetic experiments. Eur J Biochem 69(1):61-67. doi:10.1111/j.1432-1033.1976.tb10858.x

Atukeren E (2010) The relationship between the F-test and the Schwarz criterion: implications for Granger-causality tests. Econ Bull 30(1):494-499

Barcroft J, Camis M (1909) The dissociation curve of blood. J Physiol 39:118-142

Burnham KP, Anderson DR (2002) Model selection and multimodel inference: a practical information-theoretic approach, 2nd edn. Springer, New York

Chien SH, Clayton WR (1980) Application of Elovich equation to the kinetics of phosphate release and sorption in soils. Soil Sci Soc Am J 44:265-268

Chowdhury S, Das P (2011) Linear and non-linear regression analyses for binary sorpotion kinetics of methylene blue and safranin onto preheated rice husk. Bioremediat J 15:99-108

Diaz-Nava C, Olguin MT, Solache-Rios M, Alarcon-Herrera MT, Aguilar-Elguezabal A (2008) Effects of preparation and experimental conditions on removal of phenol by surfactant-modified zeolites. Environ Technol 29:1229-1239

Dimovic SD, Smiciklas ID, Sljivic-Ivanovic MZ, Plecas IB, Slavkovic-Beskoski L (2011) The effect of process parameters on kinetics and mechanisms of $\mathrm{Co} 2+$ removal by bone char. J Environ Sci Health A Tox Hazard Subst Environ Eng 46:1558-1569

El-Khaiary MI, Malash GF, Ho Y-S (2010) On the use of linearized pseudo-second-order kinetic equations for modeling adsorption systems. Desalination 257(1-3):93-101

Fan X, Parker DJ, Smith MD (2003) Adsorption kinetics of fluoride on low cost materials. Water Res 37:4929-4937 
Foubert I, Vanrolleghem PA, Vanhoutte B, Dewettinck K (2002) Dynamic mathematical model of the crystallization kinetics of fats. Food Res Int 35(10):945-956. doi:10.1016/S09639969(02)00157-6

Giraldo J, Vivas NM, Vila E, Badia A (2002) Assessing the (a)symmetry of concentration-effect curves: empirical versus mechanistic models. Pharmacol Ther 95(1):21-45. doi:10.1016/ s0163-7258(02)00223-1

Gottschalk PG, Dunn Jr (2005) The five-parameter logistic: a characterization and comparison with the four-parameter logistic. Anal Biochem 343(1):54-65. doi:10.1016/j.ab.2005.04.035

Goutelle S, Maurin M, Rougier F, Barbaut X, Bourguignon L, Ducher M, Maire P (2008) The Hill equation: a review of its capabilities in pharmacological modelling. Fundam Clin Pharmacol 22:633-648

Hannan EJ, Quinn BG (1979) The determination of the order of an autoregression. J R Stat Soc Series B Stat Methodol 41(2):190-195. doi:10.2307/2985032

Havlin JL, Westfall DG, Olsen SR (1985) Mathematical-models for potassium release kinetics in calcareous soils. Soil Sci Soc Am J 49:371-376

Hill AV (1910) The possible effects of the aggregation of the molecules of haemoglobin on its dissociation curves. J Physiol 40:4-7

Ho Y-S (2004) Selection of optimum sorption isotherm. Carbon 42(10):2115-2116. doi:10.1016/j.carbon.2004.03.019

Ho YS (2006) Second-order kinetic model for the sorption of cadmium onto tree fern: a comparison of linear and non-linear methods. Water Res 40:110-125

Ho YS, McKay G (1998a) Comparison of chemisorption kinetic models applied to pollutant removal on various sorbents. Process Saf Environ Protect Trans Inst Chem Eng Part B 76(4):332-340

Ho YS, McKay G (1998b) The kinetics of sorption of basic dyes from aqueous solution by sphagnum moss peat. Can J Chem Eng 76(4):822-827

Ho YS, Ng JCY, McKay G (2000) Kinetics of pollutant sorption by biosorbents. Rev Sep Purifi Methods 29:189-232

Holford NHG, Sheiner LB (1981) Understanding dose-effect relationships-clinical-application of pharmacokinetic-pharmacodynamic models. Clin Pharmacokinet 6:429-453

Igwe JC, Abia AA (2007) Adsorption kinetics and intraparticulate diffusivities for bioremediation of $\mathrm{Co}$ (II), $\mathrm{Fe}$ (II) and $\mathrm{Cu}$ (II) ions from waste water using modified and unmodified maize cob. Int J Phys Sci 2:119-127

Jeffreys H (1939) Theory of probability. Oxford University Press, New York

Johnson JB, Omland KS (2004) Model selection in ecology and evolution. Trends Ecol Evol 19(2):101-108. doi:10.1016/j.tree. 2003.10.013

Kass RE (1993) Bayes factors in practice. J R Stat Soc Ser D 42(5):551-560. doi:10.2307/2348679

Kass RE, Raftery AE (1995) Bayes factors. J Am Stat Assoc 90(430):773-795. doi:10.1080/01621459.1995.10476572

Khinkis LA, Levasseur L, Faessel H, Greco WR (2003) Optimal design for estimating parameters of the 4-parameter hill model. Nonlinearity Biol Toxicol Med 1:363-377

Kumar KV, Sivanesan S (2006a) Linear and non-linear regression analysis for the sorption kinetics of methylene blue onto activated carbon. J Hazard Mater 137:1538-1544
Kumar KV, Sivanesan S (2006b) Selection of optimum sorption kinetics: comparison of linear and non-linear method. J Hazard Mater 134:277-279

Leyva-Ramos R, Rivera-Utrilla J, Medellin-Castillo NA, SanchezPolo M (2010) Kinetic modeling of fluoride adsorption from aqueous solution onto bone char. Chem Eng J 158:458-467

Low MJD (1960) Kinetics of chemisorption of gases on solids. Chem Rev 60:267-312

McKay G, Poots VJP (1980) Kinetics and diffusion-processes in color removal from effluent using wood as an adsorbent. J Chem Technol Biotechnol 30:279-292

McLintock IS (1967) The Elovich equation in chemisorption kinetics. Nature 216(5121):1204-1205

Mishra DK, Dolan KD, Yang L (2011) Bootstrap confidence intervals for the kinetic parameters of degradation of anthocyanins in grape pomace. J Food Process Eng 34(4):1220-1233. doi:10. $1111 / j .1745-4530.2009 .00425 . x$

Motlagh MB (2012) Kinetics and mechanism of copper release from selected agricultural calcareous soils of northern Iran. Soil Res 50:312-319

Motulsky H, Christopoulos A (eds) (2004) Fitting models to biological data using linear and nonlinear regression. A practical guide to curve fitting. Oxford University Press, New York

Motulsky HJ, Ransnas LA (1987) Fitting curves to data using nonlinear regression: a practical and nonmathematical review. FASEB J 1(5):365-374

Pavlatou A, Polyzopoulos NA (1988) The role of diffusion in the kinetics of phosphate desorption - the relevance of the Elovich equation. J Soil Sci 39:425-436

Perez-Marin AB, Zapata VM, Ortuno JF, Aguilar M, Saez J, Llorens M (2007) Removal of cadmium from aqueous solutions by adsorption onto orange waste. J Hazard Mater 139:122-131

Plummer LN, Wigley TML, Parkhurst DL (1978) The kinetics of calcite dissolution in $\mathrm{CO} 2$-water systems at 5 degrees to 60 degrees C and 0.0 to $1.0 \mathrm{~atm}$ CO 2. Am J Sci 278(2):179-216. doi:10.2475/ajs.278.2.179

Qian G, Field C (2002) Law of iterated logarithm and consistent model selection criterion in logistic regression. Stat Prob Lett 56 (1):101-112. doi:10.1016/S0167-7152(01)00191-2

Raftery AE (1995) Bayesian model selection in social research (with discussion). Sociol Methodol 25:111-196

Robinson T, McMullan G, Marchant R, Nigam P (2001) Remediation of dyes in textile effluent: a critical review on current treatment technologies with a proposed alternative. Bioresour Technol 77(3):247-255. doi:10.1016/S0960-8524(00)00080-8

Roginsky S. Z., Zeldovich J (1943). Acta Physicochim USSR (1):554

Schwarz G (1978) Estimating the dimension of a model. (2):461-464. doi:10.1214/aos/1176344136

Sleap SB, Turner BD, Krabbenhoft K, Sloan SW (2013) Effects of $\mathrm{pCO}(2)$ on the removal of fluoride from wastewater by calcite. J Environ Eng 139(8):1053-1061

Smadbeck P, Kaznessis Y (2012) Stochastic model reduction using a modified Hill-type kinetic rate law. J Chem Phys 137(23):34109

Stone M (2005) Akaike's Criteria. In: Encyclopedia of biostatistics. Wiley. doi:10.1002/0470011815.b2a09001

Sun Q, McDonald LM Jr, Skousen JG (2000) Effects of armouring on limestone neutralization of AMD. In: Proceedngs of the 2000 West Virginia surface mine drainage task force symposium, Morgantown, WV 
Wagenmakers E-J (2007) A practical solution to the pervasive problems of p values. Psychon Bull Rev 14(5):779-804. doi:10. 3758/bf03194105

Wagenmakers E-J, Farrell S (2004) AIC model selection using Akaike weights. Psychon Bull Rev 11(1):192-196. doi:10.3758/ bf03206482
Weber J, Morris JC (1963) Kinetics of adsorption on carbon from solution. J Sanitary Eng Div Proceed Am Soc Civil Eng 89:31-59

Wen DH, Ho YS, Tang XY (2006) Comparative sorption kinetic studies of ammonium onto zeolite. $\mathrm{J}$ Hazard Mater 133(1-3):252-256. doi:10.1016/j.jhazmat.2005.10.020 